\title{
Effect of Watering Regime on Disease Development in Pinus sylvestris Seedlings Inoculated with Bursaphelenchus vallesianus and B. mucronatus
}

\author{
J. Polomski and D. Rigling, WSL Swiss Federal Research Institute, 8903 Birmensdorf, Switzerland
}

\begin{abstract}
Polomski, J., and Rigling, D. 2010. Effect of watering regime on disease development in Pinus sylvestris seedlings inoculated with Bursaphelenchus vallesianus and B. mucronatus. Plant Dis. 94:1055-1061.

Several Bursaphelenchus spp. have been detected in declining pine trees in Europe during intensive monitoring for the pine wood nematode B. xylophilus. We investigated the pathogenicity of B. vallesianus and B. mucronatus, isolated from declining Scots pine (Pinus sylvestris) forests in Valais (Switzerland), in relation to drought stress. Four isolates of $B$. vallesianus and two isolates of B. mucronatus were inoculated into 3-year-old P. sylvestris trees, which were subjected to different watering treatments $(50,100,150$, and $250 \mathrm{ml}$ of water per pot, biweekly). Disease symptoms, plant mortality, nematode population density, and nematode distribution in dead plants were assessed. Both Bursaphelenchus spp. proved highly pathogenic to the seedlings and watering treatment affected disease development in the inoculated pine trees. With decreasing water supply, we observed faster disease progress and higher pine mortality for both Bursaphelenchus spp.. The overall mortality 70 days after inoculation was $60,92,95$, and $100 \%$ for $B$. vallesianus and 40,95, 100, and $100 \%$ for B. mucronatus in the 250-, 150-, 100-, and 50-ml watering treatments, respectively. Both nematode species multiplied in the inoculated plants; however, B. mucronatus had higher population densities than $B$. vallesianus in all watering treatments (on average, 33,159 versus 14,702 nematodes/dead plant compared with the initial inoculum density of 6,000 nematodes/plant). The highest nematode density was found in the lower part of the stem. About 7 to $16 \%$ of the nematodes were extracted from the roots. This study demonstrated that $B$. vallesianus has a pathogenicity potential comparable with that of $B$. mucronatus and provided experimental evidence that drought stress can result in increased symptoms caused by either Bursaphelenchus sp.
\end{abstract}

Numerous species of the nematodes in the genus Bursaphelenchus have been detected in coniferous forests worldwide $(1,2,6,10,30,36,61)$. Research has focused mainly on one species, the highly pathogenic Bursaphelenchus xylophilus. This species, commonly known as pine wood nematode, is a causal agent of pine wilt disease (PWD) and has occurred epidemically in pine forests in Japan, China, and other Asian countries for many years, causing substantial economic losses $(15,56,61)$. In Europe (Portugal), B. xylophilus was first recorded in 1999 on Pinus pinaster (42). This finding initiated an intensive search in the pine forests of several European countries for Bursaphelenchus nematodes, which were found to occur frequently in Europe. The most common species are B. mucronatus and various members of the $B$. sexdentati group $(12,14,16,41,53)$. In Valais (Switzerland), B. vallesianus and B. mucronatus were found in almost half of the recently

Corresponding author: J. Polomski

E-mail: janina.polomski@wsl.ch

Accepted for publication 27 April 2010.

doi:10.1094/PDIS-94-8-1055

(C) 2010 The American Phytopathological Society dead pine trees ( $P$. sylvestris), probably as secondary invaders after insect attacks $(48,60)$. A decline of the pine forests has been observed for decades in Valais but, within the past 10 years, nearly $50 \%$ of local pine trees have died $(5,20,49)$. Although the causes of pine decline appear very complex, increased summer temperatures and drought episodes seem to be important initiating factors (49).

In trees, drought stress and reduced water supply to the leaves causes a decrease in the photosynthesis rate followed by a reduction in water potential, which may severely weaken the plants $(24-26,45)$. A low water potential may induce cavitation and, consequently, embolism of tracheides by breaking the water column in xylem and impairing the water transport in the plant $(58,62)$. Several reports indicate that plants subjected to drought stress become more susceptible to pathogens and insect pests $(17,19,45,51,55)$. Drought may also affect trees indirectly by interacting with wilt-inducing vascular pathogens, reducing tolerance and promoting disease outbreak. Epidemiological investigations of B. xylophilus suggested that drought stress in combination with high temperatures (mean $>20^{\circ} \mathrm{C}$ ) were key factors in the establishment and spread of PWD in Asian countries $(27,36,52)$. B. xylophilus has rapidly killed pine trees under such favorable con- ditions in Japan or China, whereas pine wilt remains latent during cold and rainy weather for months or years $(27,36)$. Several inoculation experiments indicated that other Bursaphelenchus spp. were pathogenic $(3,4,9,11,38,41,47)$. B. mucronatus and B. sexdentati, for example, killed 2- to 4-year-old pine seedlings, although the mortality rate varied greatly depending on the host species, origin of nematode isolates, and climatic factors such as temperature and water status $(9,11,50)$. B. mucronatus was also inoculated into larger trees but did not cause significantly mortality and disease symptoms when compared with B. xylophilus (38). However, other Japanese isolates of $B$. mucronatus also proved to have similarly low pathogenicity in the inoculated pine seedlings (38).

Even though the occurrence of various Bursaphelenchus spp. in declining pine forests in Europe has frequently been reported, their role in the decline process remains largely unknown. Few experimental studies have been conducted to evaluate the interaction between the nematodes and the environmental factors thought to be involved in pine decline. The aim of the present study was to assess (i) the pathogenicity to Scots pine of $B$. vallesianus and $B$. mucronatus isolated in Valais and (ii) the effect of watering treatments on disease development by the two Bursaphelenchus spp.

\section{MATERIALS AND METHODS}

Plant material and growth conditions. Seedlings of $P$. sylvestris (3 years old; provenance: Tschlin, Switzerland) were used for the inoculation experiment. In April 2005, bare-root plants were transplanted into 3.7-liter pots filled with an organic substrate consisting of $67 \%$ garden mould (bark humus, peat, and wood fiber) and $33 \%$ wood fiber. The potted pine seedlings were kept outdoors and watered as required. Four weeks before inoculation, the pots were brought into a greenhouse and placed in water-filled trays for $48 \mathrm{~h}$ to saturate the substrate with water. The pots were placed on water-free trays and allowed to drain for 3 days to achieve field water capacity (FWC). According to Mückenhausen (43), FWC was assumed to be $80 \%$ of the total water capacity (TWC) in organic soils, and was calculated as $59 \%$ of water volume in the substrate used in our experiment. TWC of the growth substrate was determined from three water-saturated substrate cores $\left(150 \mathrm{~cm}^{3}\right)$ dried at $105^{\circ} \mathrm{C}$ to a constant 
weight and expressed as the percentage of water volume per substrate volume. Available water content (AWC) was assessed during the course of the experiment in extra pots in three replications for each watering treatment. From each of these pots, core samples $\left(25 \mathrm{~cm}^{3}\right)$ were taken twice a week before watering. The substrate was dried at $60^{\circ} \mathrm{C}$ for $24 \mathrm{~h}$ and $\mathrm{AWC}$ was expressed as the percentage of water volume per substrate volume taken (Vol\%).

Temperature in the greenhouse fluctuated with the outside sunshine and temperature conditions. The daily mean temperature (average of maximum and minimum temperatures) in the greenhouse was $25^{\circ} \mathrm{C}$ in July, $23^{\circ} \mathrm{C}$ in August, and $22^{\circ} \mathrm{C}$ in September. The mean maximum temperature was $30^{\circ} \mathrm{C}$ in July, $28^{\circ} \mathrm{C}$ in August, and $27^{\circ} \mathrm{C}$ in September and the mean minimum temperature was 20,17 , and $17^{\circ} \mathrm{C}$, respectively.

Watering treatments. After FWC was reached in the substrate as described in the previous section, the plants were watered with tap water biweekly with one of four volumes per pot: $50,100,150$, and $250 \mathrm{ml}$ The watering treatments corresponded, on average, to an AWC of 39, 42, 46, and $53 \%$ in the growth substrate, respectively (mean of all samples per watering treatment). These values were above the "permanent wilting point", which is $20 \%$ AWC in an organic substrate (43), but below the estimated $59 \%$ FWC.
Nematode inoculation. The $B$. vallesianus and B. mucronatus isolates used in this study were extracted from declining pine trees ( $P$. sylvestris) at two sites, Salgesch and Stalden in Valais (Switzerland), in March 2005 as described by Polomski et al. (48). Four isolates of B. vallesianus (three from Salgesch and one from Stalden) and two isolates of B. mucronatus (one from Salgesch and one from Stalden) were used. The isolates were identified to species by the standard internal transcribed spacer-restriction fragment length polymorphism technique (11). To produce inoculum, the isolates were reared on Botrytis cinerea mycelium grown on malt agar in $9-\mathrm{cm}$ petri dishes at $25^{\circ} \mathrm{C}$ in the dark. Nematodes were extracted in distilled water in Baermann funnels (57) 1 day before inoculation. The plants were inoculated between 18 and 22 July 2005, as described by Braasch et al. (11). A longitudinal slit about $1 \mathrm{~cm}$ long was cut with a scalpel in the bark at the base of the previous year's main shoot, and a sterilized cotton strip was inserted into the slit. Each plant was inoculated with $0.5 \mathrm{ml}$ of distilled water containing 6,000 nematodes. This inoculum level was chosen based on previous studies in which 6,000 to 10,000 nematodes per plant were applied $(9,27,29,31,54)$. The inoculation site was also adopted from other studies $(11,18,54)$ to allow better comparison of the results. The nematode suspension was dropped
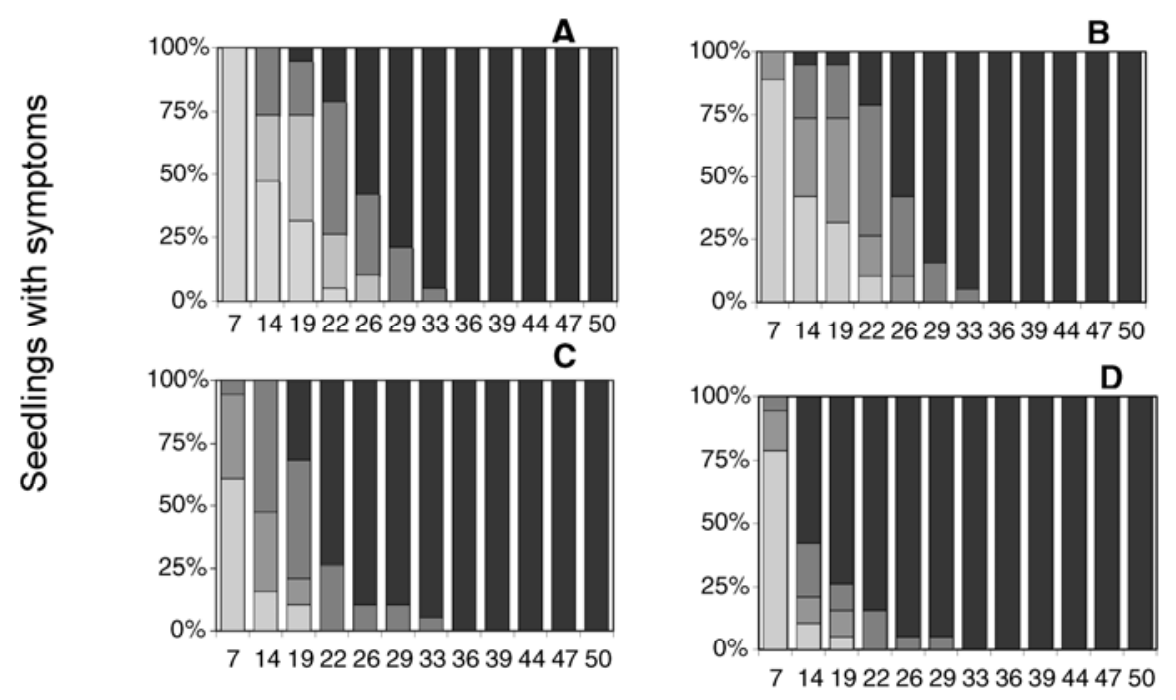

Days after inoculations

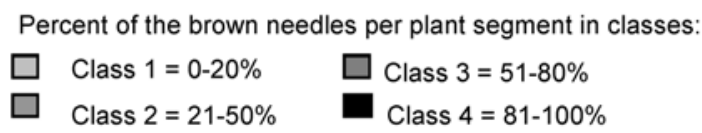

Fig. 1. Progress of needle discoloration in 3-year-old Scots pine (Pinus sylvestris) seedlings inoculated with Bursaphelenchus mucronatus in the 50-ml watering treatment. Symptom development was assessed as the percentage of seedlings showing needle browning for each of four discoloration classes (class $1=0$ to $20 \%$, class $2=21$ to $50 \%$, class $3=51$ to $80 \%$, and class $4=81$ to $100 \%$ discolored needles). Data were the means of 10 replications and were pooled over two isolates $(n=20)$. A, Stem above the inoculation sites. B, Branches above the inoculation sites. C, Stem below the inoculation sites. D, Branches below the inoculation sites.

onto the cotton strip and the inoculation site was wrapped with polyethylene plastic foil to retain moisture. Each nematode isolate was inoculated into 10 plants per watering treatment. Two pots were accidentally lost during inoculations, resulting in a total of 159 plants inoculated with $B$. vallesianus and 79 plants with $B$. mucronatus. Ten plants per treatment (in total, 40 plants) were inoculated with distilled water and served as controls. Additionally, 10 control plants were inoculated with an extract from a nematode-free $B$. cinerea culture to examine the impact of fungus alone on the plants.

Assessment of disease symptoms. Needle discoloration and plant wilting were evaluated twice a week for 10 weeks on four distinct segments of each plant: (i) the stem above the inoculation site, (ii) the branches above the inoculation site, (iii) the stem below the inoculation site, and (iv) the branches below the inoculation site. The severity of needle discoloration was classified for each plant segment according to the following scale: class $1=0$ to $20 \%$, class $2=21$ to $50 \%$, class $3=51$ to $80 \%$, and class $4=81$ to $100 \%$ discolored needles. The plant was considered dead if needle discoloration had reached class 4 on all the plant segments.

Nematode extraction and reproduction potential. Dead plants were harvested immediately and cut into three segments: (i) plant segment above the inoculation point, (ii) branches, and (iii) stem below the inoculation point. The nematode distribution pattern was determined in more detail in the plants subjected to the 50-ml watering treatment, in which the stem part below the inoculation site was cut in half (resulting in a middle and lower part of stem) and coarse roots ( $>2 \mathrm{~mm}$ in diameter) were included in the nematode extraction. Nematodes were extracted from each plant segment separately on Baermann funnels (57). The reproduction potential of the nematodes was expressed as the number of reisolated nematodes per plant (NN). The nematode density was calculated as the number of nematodes per gram fresh weight (NC). The reproduction ratio was calculated by dividing the number of nematodes isolated at harvest by the number of nematodes inoculated per plant (reproduction rate $[R R]$ ).

Statistical analysis. All statistical analyses were performed with the program Data Desk (version 6.1; Data Description Inc., Ithaca, NY). Logistic regression and Scheffe post-hoc tests were used to test for differences in plant mortality among Bursaphelenchus spp., isolates, and watering treatments. In this analysis, plant mortality was the dependent binary variable, expressed as dead $=1$ and alive $=0$ for each seedling. The explanatory (independent) variables were Bursaphelenchus sp. and isolate (nested in the variable "species") that were inoculated into the seedlings, and 
watering treatment. Differences in nematode population in the dead plants, calculated as NN, NC, and RR among species, isolates, and watering treatments, were evaluated with analysis of variance (ANOVA) and Scheffe post-hoc tests. NN, $\mathrm{NC}$, and RR were the dependent variables and species, isolates, and watering treatment were the explanatory variables in this analysis. The distribution of Bursaphelenchus mucronatus and B. vallesianus in the dead plants was examined by comparing the NC (= dependent variable) among the different plant segments (= explanatory variables) with ANOVA and Scheffe posthoc tests. Regression analysis was used to assess the relationship between the nematode population $(\mathrm{NN}$ and $\mathrm{NC}=$ dependent variables) and the plant size (stem diameter and plant height $=$ independent variables). Data for NN, NC, and RR were log-transformed before these analyses. The significance level for all statistical tests was set at $P<0.05$.

\section{RESULTS}

Symptom development. $B$. vallesianus and $B$. mucronatus induced serious symptoms in the inoculated pine seedlings. Damage appeared as a yellowing and browning of the needles on the stem and branches and, finally, resulted in wilting of the whole plant. No differences were observed in symptom expression and spread between the two Bursaphelenchus spp. A typical pattern of symptom development was observed for pine seedlings inoculated with $B$. mucronatus and given the 50-ml watering treatment (Fig. 1). The first symptoms became visible about 7 days after inoculation (on average, 11 days after inoculation for both species; Table 1) and progressed rapidly, primarily on the older needles below the inoculation site (Fig. 1C and D) and later on the needles above the inoculation site (Fig. 1A and B). On average, half of the plants manifested a total needle discoloration (class 4) on the stem below the inoculation site within 14 days of inoculation, on the branches below the inoculation site within 21 days of inoculation, and on the plant segments above the inoculation site 1 week later (i.e., within 28 days of inoculation) (Fig. 1). Low watering accelerated the onset of symptom development. Needles discolored earlier in the 50-ml than in the 250-ml treatment; on average, 4 days earlier for $B$. vallesianus and 12 days earlier for $B$. mucronatus (Table 1). The control plants in all watering treatments remained symptomless throughout the 70-day observation period. No symptoms were observed on the control plants inoculated with Botrytis cinerea, which verifies that the plant symptoms were solely nematode-induced.

Mortality. The final mortality rate of all inoculated pine seedlings was very high for both Bursaphelenchus spp.; on average, Bursaphelenchus vallesianus killed $86 \%$ of the plants and B. mucronatus killed $84 \%$ (Table 1). Logistic regression analysis showed no significant differences in mortality rates between species $(F=0.265, P=$ $0.607)$ and among isolates within species (two isolates of $B$. mucronatus: $F=0.065$, $P=0.803$; four isolates of $B$. vallesianus: $F=0.059, P=0.622$ ). The progress and rate of plant mortality, however, were significantly affected by the watering treatments (Table 1). The plants subjected to the 50-ml treatment showed first mortality 16 days earlier for $B$. mucronatus and 8 days earlier for $B$. vallesianus than the well-watered plants $(250 \mathrm{ml})$. The mean time required for $B$. mucronatus to kill $25 \%$ of the inoculated plants was nearly three times less at low watering conditions: only 22 days in the 50-ml treatment compared with 64 days in the $250-\mathrm{ml}$ treatment. For B. vallesianus, the difference was not so great but the mean time still increased from 27 days in the $50-\mathrm{ml}$ treatment up to 40 days in the $250-\mathrm{ml}$ treatment (Fig. 2A and B). The mean mortality rate was $100 \%$ in the $50-\mathrm{ml}$ treatment and was also high in the 100- and $150-\mathrm{ml}$ treatments (92 to $100 \%$ ); it decreased significantly, to $60 \%$ for B. vallesianus and $40 \%$ for B. mucronatus, in the 250-ml treatment (Table 1; Fig. 2A and B).

NC in dead seedlings. Both Bursaphelenchus spp. reproduced in the inoculated plants but $B$. mucronatus had a significantly higher mean RR than $B$. vallesianus over all treatments (viz., 5.7 and 2.5, respectively; Table 2). Likewise, the NN and NC were much higher for $B$. mucronatus than for B. vallesianus in all watering treatments (Table 2). There was no effect of watering treatments on the population densities of both Bursaphelenchus spp.

Table 1. Effect of watering treatments on disease development and mortality in 3-year-old Pinus sylvestris inoculated with Bursaphelenchus vallesianus (four isolates) and B. mucronatus (two isolates)

\begin{tabular}{|c|c|c|c|c|c|c|}
\hline \multirow[b]{2}{*}{ Isolates } & \multirow[b]{2}{*}{ Treatment $(\mathrm{ml})^{\mathrm{y}}$} & \multirow[b]{2}{*}{$n^{\mathbf{z}}$} & \multicolumn{2}{|c|}{ Onset (dai) of ${ }^{w}$} & \multicolumn{2}{|c|}{ Tree mortality $^{x}$} \\
\hline & & & Symptoms & Mortality & $n$ & Percent \\
\hline \multicolumn{7}{|l|}{ B. vallesianus } \\
\hline bvsa136 & 50 & 10 & 12 & 24 & 10 & 100 \\
\hline bvsa(136/8) & $\ldots$ & 10 & 12 & 24 & 10 & 100 \\
\hline bvsa8 & $\ldots$ & 10 & 12 & 31 & 10 & 100 \\
\hline bvst179 & $\ldots$ & 10 & 9 & 24 & 10 & 100 \\
\hline Sum or Mean & $\ldots$ & 40 & 11 & 26 & 40 & $100 \mathrm{a}$ \\
\hline bvsa136 & 100 & 10 & 12 & 24 & 9 & 90 \\
\hline bvsa(136/8) & $\ldots$ & 10 & 12 & 24 & 10 & 100 \\
\hline bvsa8 & $\ldots$ & 10 & 12 & 27 & 10 & 100 \\
\hline bvst179 & $\ldots$ & 10 & 14 & 24 & 8 & 80 \\
\hline Sum or Mean & $\ldots$ & 40 & 13 & 25 & 37 & $95 \mathrm{a}$ \\
\hline bvsa136 & 150 & 10 & 19 & 42 & 9 & 90 \\
\hline bvsa(136/8) & $\ldots$ & 10 & 12 & 38 & 9 & 90 \\
\hline bvsa8 & $\ldots$ & 9 & 12 & 34 & 8 & 89 \\
\hline bvst179 & $\ldots$ & 10 & 21 & 31 & 10 & 100 \\
\hline Sum or Mean & . & 39 & 16 & 36 & 36 & $92 \mathrm{a}$ \\
\hline bvsa136 & 250 & 10 & 12 & 34 & 7 & 70 \\
\hline bvsa(136/8) & $\ldots$ & 10 & 12 & 34 & 7 & 70 \\
\hline bvsa8 & $\ldots$ & 10 & 19 & 31 & 6 & 60 \\
\hline bvst179 & $\ldots$ & 10 & 15 & 31 & 4 & 40 \\
\hline Sum/Mean & $\ldots$ & 40 & 15 & 33 & 24 & $60 \mathrm{~b}$ \\
\hline $\begin{array}{l}\text { Total } \\
\text { Sum/Mean }\end{array}$ & $\ldots$ & 159 & 14 & 30 & 137 & 86 \\
\hline \multicolumn{7}{|l|}{$\begin{array}{l}\text { Sum/Mean } \\
\text { B. mucronatus }\end{array}$} \\
\hline $\operatorname{bmsa}(240 / 205)$ & 50 & 9 & 14 & 22 & 9 & 100 \\
\hline bmst 80 & $\ldots$ & 10 & 7 & 19 & 10 & 100 \\
\hline Sum or Mean & $\ldots$ & 19 & 11 & 21 & 19 & $100 \mathrm{a}$ \\
\hline $\operatorname{bmsa}(240 / 205)$ & 100 & 10 & 14 & 19 & 10 & 100 \\
\hline bmst80 & $\ldots$ & 10 & 7 & 22 & 10 & 100 \\
\hline Sum or Mean & & 20 & 11 & 21 & 20 & $100 \mathrm{a}$ \\
\hline $\operatorname{bmsa}(240 / 205)$ & 150 & 10 & 14 & 26 & 10 & 100 \\
\hline bmst 80 & $\ldots$ & 10 & 14 & 26 & 9 & 90 \\
\hline Sum or Mean & $\ldots$ & 20 & 14 & 26 & 19 & $95 \mathrm{a}$ \\
\hline bmsa(240/205) & 250 & 10 & 19 & 36 & 4 & 40 \\
\hline bmst80 & $\ldots$ & 10 & 26 & 39 & 4 & 40 \\
\hline Sum or Mean & $\ldots$ & 20 & 23 & 38 & 8 & $40 \mathrm{~b}$ \\
\hline Total & $\ldots$ & 79 & 15 & 26 & 66 & 84 \\
\hline Sum/Mean & & & & & & \\
\hline Control & All & 40 & no & no & 0 & 0 \\
\hline
\end{tabular}

${ }^{\mathrm{w}}$ Onset at days after inoculation (dai).

${ }^{\mathrm{x}}$ Tree mortality 10 weeks after inoculation. Mean mortality rates within species followed by different letters are significantly different among watering treatments $(P<0.05)$ according to logistic regression model and Scheffe post-hoc tests.

${ }^{\mathrm{y}}$ Watering treatment, performed biweekly and measured in milliliters per pot; All = 50, 100, 150, and $250 \mathrm{ml} / \mathrm{pot}$.

${ }^{\mathrm{z}}$ Number of plants. Each nematode isolate was inoculated into 10 plants per watering treatment and 10 control plants per watering treatments were inoculated with water. 
The total NN and the RR tended to be lower in the low- versus high-watering treatments but this difference was only statistically significant for B. vallesianus. No relationship was found between NC and plant size (plant height and stem diameter) for either $B$. vallesianus or $B$. mucronatus but the total NN seemed to be dependent on the plant height $\left(R^{2}=13.1 \%\right.$, $P=0.0016$ for B. mucronatus and $R^{2}=$ $14.9 \%, P<0.0001$ for $B$. vallesianus).

Nematode distribution in dead seedlings. Nematodes migrated upward and downward from the inoculation site throughout the plant and were recovered from the branches, stem, and roots of the dead plants (Fig. 3). The distribution pattern was very similar for both nematode species and for all isolates, and was also comparable among the watering treatments. On average, 75 and $79 \%$ of the $B$. mucronatus and $B$. vallesianus population was concentrated in the stem below the inoculation point, whereas the lowest proportion of nematodes was found in the branches $(16 \%)$ and in the upper part of the plants (9 and 5\%, respectively). More detailed examination of the nematode distribution in the plants subjected to the 50$\mathrm{ml}$ treatment confirmed that the nematode population was highest in the stem below the inoculation site and lowest in the upper plant above the inoculation site (Fig. 3). The NC in the coarse roots of the dead pine trees reached 219 and 203 nematodes/g fresh weight for B. vallesianus and B. mucronatus, respectively. When considering the total number of nematodes in
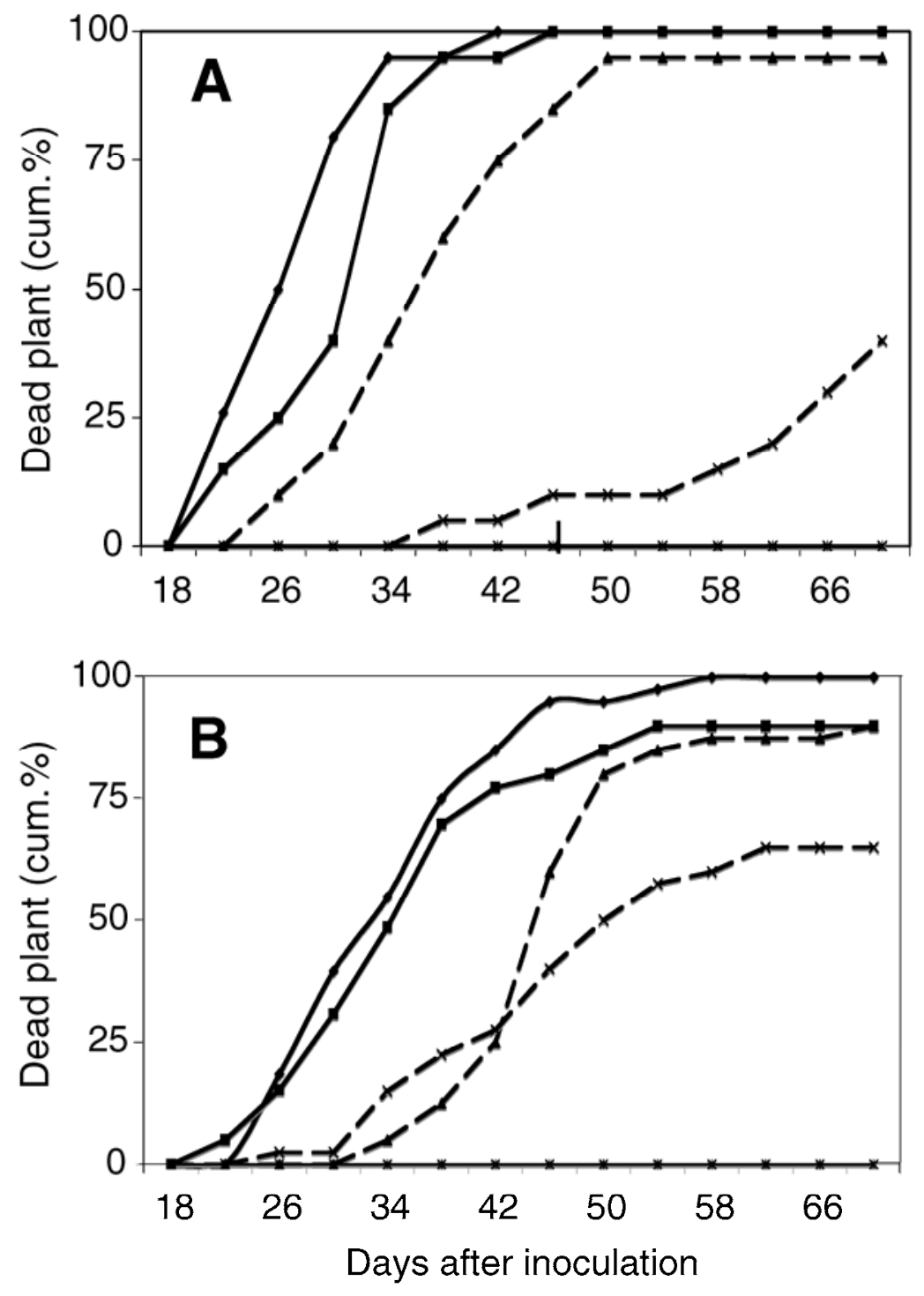

$\rightarrow 50 \mathrm{ml} \rightarrow-100 \mathrm{ml} \rightarrow-150 \mathrm{ml} \rightarrow-250 \mathrm{ml} \rightarrow$ Control

Fig. 2. Progress of mortality of Scots pine seedlings (Pinus sylvestris) inoculated with A, Bursaphelenchus mucronatus and $\mathbf{B}, B$. vallesianus. Mortality is shown as the cumulative percentages of dead seedlings in the four watering treatments: $50,100,150$, or $250 \mathrm{ml}$ of water per pot, biweekly. Data represent means of 10 replications and were pooled over the two isolates for B. mucronatus $(n=20)$ and four isolates for B. vallesianus $(n=40)$. Ten control plants per watering treatment that had been inoculated with distilled water showed no mortality. 
150-ml watering treatment than $B$. vallesianus. This could be explained by the significantly higher reproduction potential of B. mucronatus found in each watering treatment. The ability of Bursaphelenchus spp. to multiply rapidly and develop high population densities in host plants has been regarded as an important factor promoting disease development and mortality $(4,9,18$, 21,40).

The higher pathogenicity potential of $B$. mucronatus may be due to its close similarity to B. xylophilus. Based on both morphological and phylogenetic analysis, $B$. mucronatus is the closest relative to $B$. xylophilus, whereas $B$. vallesianus is clearly distinct (10).

However, the consistently lower number of B. vallesianus in the dead plants could also mean that this nematode species requires lower population levels to cause mortality than B. mucronatus. It is also interesting to note that $B$. vallesianus was more aggressive than $B$. mucronatus in the 250-ml watering treatment. This observation could indicate that $B$. vallesianus is better at causing disease in well-watered plants.

In contrast to the large difference in the reproduction potential of the two species, no major differences were observed in the symptom expression induced by $B$. vallesianus and $B$. mucronatus manifested as needle discoloration and necrosis above and below the inoculation site of the inoculated plants. Moreover, the symptoms were very similar to those manifested on various pine species inoculated with $B$. xylophilus $(28,29,31,35,37,59)$. It seems to be typical of Bursaphelenchus spp.induced symptoms under comparable experimental conditions to have a rapid spread and increase in the nematode population density, which results in needle discoloration and plant wilt within a short period of 3 to 4 weeks after inoculation.
The minimum population level required to trigger disease and to spread symptoms could not be determined definitely in previous studies $(7,18,21,40)$, nor was it clear in our results. However, our statistical analysis was hampered by high variation in the NC among plants, with a mean standard deviation ranging from 50 to $150 \%$. Other studies have also found high variability in the population densities of nematodes in pine seedlings inoculated with $B$. mucronatus, B. sexdentati, or B. xylophilus $(4,9,18,38,54)$. In addition, the reproduction dynamic of the nematodes during the first days after inoculation, not examined in our experiment, could be more decisive for disease development than the final nematode population estimated in the dead seedlings. Melakeberhan and Webster (40) found a dramatic decline of the initial nematode population immediately after inoculation followed by an exponential reproduction of the nematodes associated with wilting symptoms.

The nematode distribution followed a very similar pattern for both species studied and was comparable with that observed for B. xylophilus in inoculated pine seed-

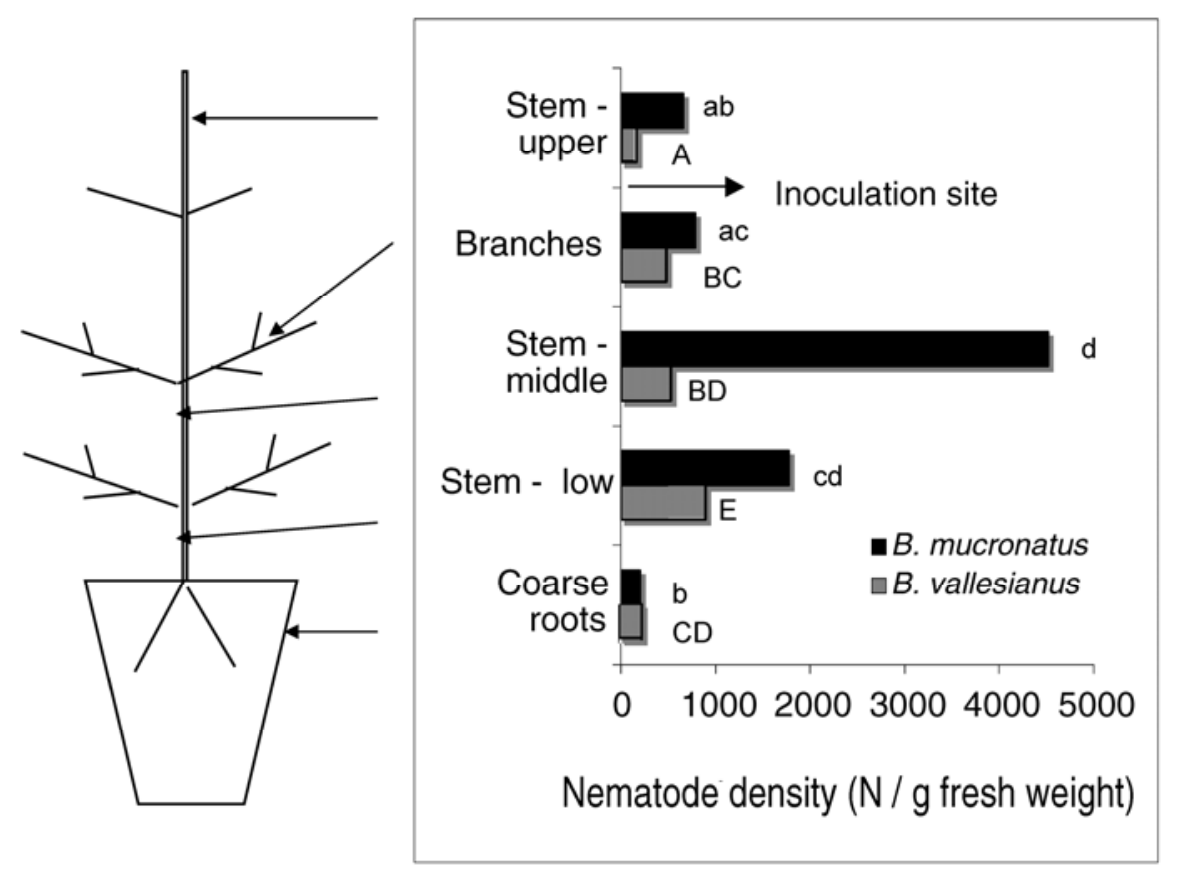

Fig. 3. Distribution of Bursaphelenchus vallesianus and B. mucronatus in the Scots pine (Pinus sylvestris) seedlings subjected to the 50-ml watering treatment (milliliters of water per pot, biweekly) at the time of pine death. The nematode population in each plant segment is expressed as nematode density. Data were pooled over two isolates for B. mucronatus and four isolates for B. vallesianus. Bars marked with the same letter within the nematode species indicate mean values that are not significantly different (analysis of variance and Scheffe post-hoc tests, $P<0.05$ ).

Table 2. Bursaphelenchus vallesianus and B. mucronatus populations in 3-year-old Scots pine trees (Pinus sylvestris) at the time of pine death in four different watering treatments ${ }^{\mathrm{v}}$

\begin{tabular}{|c|c|c|c|c|c|c|c|c|c|}
\hline \multirow[b]{2}{*}{ Treatments $(\mathrm{ml})^{\mathrm{y}}$} & \multirow[b]{2}{*}{$n$} & \multicolumn{4}{|c|}{ No. of nematodes/plant ${ }^{w}$} & \multicolumn{3}{|c|}{ Nematode density (no./g fresh weight $)^{x}$} & \multirow[b]{2}{*}{$\mathbf{R R}^{\mathbf{z}}$} \\
\hline & & Min. & Max. & Mean & SD $(\%)$ & Min. & Max. & Mean & \\
\hline \multicolumn{10}{|l|}{ B. vallesianus } \\
\hline 50 & 40 & 3,429 & 103,770 & $19,026 \mathrm{a}$ & 92 & 105 & 2,118 & 464 a & $3.2 \mathrm{a}$ \\
\hline 100 & 37 & 1,750 & 44,500 & $17,629 \mathrm{ab}$ & 75 & 34 & 1,873 & $657 \mathrm{a}$ & $2.9 \mathrm{ab}$ \\
\hline 150 & 36 & 1,705 & 31,020 & $9,798 \mathrm{ab}$ & 69 & 81 & 1,108 & $385 \mathrm{a}$ & $1.6 \mathrm{bc}$ \\
\hline 250 & 24 & 764 & 79,700 & $12,353 \mathrm{~b}$ & 151 & 85 & 4,195 & $614 \mathrm{a}$ & $2.1 \mathrm{c}$ \\
\hline Mean & & 1,912 & 64,747 & 14,702 & 97 & 76 & 2,323 & 530 & 2.5 \\
\hline \multicolumn{10}{|l|}{ B. mucronatus } \\
\hline 50 & 19 & 5,041 & 113,775 & $43,623 \mathrm{a}$ & 71 & 370 & 2,211 & $1,051 \mathrm{a}$ & $7.3 \mathrm{a}$ \\
\hline 100 & 20 & 9,100 & 55,825 & $28,542 \mathrm{a}$ & 53 & 225 & 2,304 & $1,201 \mathrm{a}$ & $4.5 \mathrm{a}$ \\
\hline 150 & 19 & 6,155 & 75,110 & $31,945 \mathrm{a}$ & 68 & 327 & 5,274 & $1,450 \mathrm{a}$ & $5.3 \mathrm{a}$ \\
\hline 250 & 8 & 1,910 & 75,970 & $36,525 \mathrm{a}$ & 105 & 32 & 2,187 & $1,105 \mathrm{a}$ & $6.1 \mathrm{a}$ \\
\hline Mean & $\ldots$ & 7,904 & 80,170 & 33,159 & 74 & 238 & 2,994 & 1,202 & 5.7 \\
\hline
\end{tabular}

${ }^{\mathrm{v}}$ Means within a column and species followed by the same letters are not significantly different $(P<0.05)$ among watering treatments (analysis of variance and Scheffe post-hoc tests).

${ }^{w}$ Number of nematodes per plant. Minimum (Min.), maximum (Max.), and mean values ( \pm percent standard deviation [SD]) are given.

${ }^{x}$ Number of nematodes per gram fresh weight. Min., Max., and Mean values are given.

${ }^{\mathrm{y}}$ Watering treatment, performed biweekly and measured in milliliters per pot. Data were pooled over four isolates of $B$. vallesianus and two isolates of $B$. mucronatus for 10 replicates per watering treatment.

${ }^{\mathrm{z}}$ Reproduction rate $(\mathrm{RR})=$ number of reisolated nematodes in the dead plant/number of inoculated nematodes per plant $(6,000)$. 
lings $(18,33)$. It is not clear which factors control nematode migration in the plant. Kuroda (31) and Utsuzawa et al. (59) reported that B. xylophilus, for example, moved as cavitation was spreading in the xylem and that anatomical features of the host wood strongly affected nematode migration $(32,33)$. The water gradient along the plant could also affect the nematode distribution. Daub (18) found a positive correlation between the density of $B$. xylophilus and the water content in the stem base and the roots of inoculated $P$. sylvestris. We detected the presence $B$. vallesianus and $B$. mucronatus in both the coarse and the fine roots $(<1 \mathrm{~mm}$ in diameter) of plants. Several investigators $(11,18,29,40,44)$ have detected Bursaphelenchus nematodes in plant roots but it is not clear whether the occurrence of Bursaphelenchus spp. in the roots is biologically relevant. Blakeslee et al. (6), hypothesized that Bursaphelenchus nematodes could be transmitted from tree to tree via root grafts. Root grafts are relatively common in mature pine forests and have been suggested as a potential conduit between trees for transmitting water and mineral nutrients but also certain pathogens (46). Vascular pathogens, such as Ophiostoma ulmi (cause of Dutch elm disease) or Ceratocystis fagacearum (cause of oak wilt), are known to spread through root grafts, which can result in extensive tree mortality in areas where host trees are closely spaced $(13,34)$. Whether root-to-root transmission is also relevant for Bursaphelenchus nematodes needs to be shown,

This study has demonstrated the ability of $B$. vallesianus and B. mucronatus to destroy living plant tissue and induce the death of pine seedlings under experimental conditions. It has also shown that watering regimes affect the degree of mortality. Our results suggest that the symptom expression and disease pattern induced by the two Bursaphelenchus spp. are very similar and comparable with those described for B. xylophilus in inoculated pine seedlings.

However, we cannot claim, based on our experiments alone, to have the final verdict about the ability of nematodes other than $B$. xylophilus to kill mature pine trees in the forest. First, the adverse effect of nematodes on younger trees can be more severe than on older trees (39). Second, trees are artificially inoculated with nematodes in such studies whereas, in the forest, insect vectors transmit nematodes (36). Thus, disease epidemics are influenced not only by the pathogenicity and virulence of nematodes but also by the life cycle and population dynamics of vectors and the efficiency of nematode transmission (both B. mucronatus and B. xylophilus are dispersed by Monochamus sp. [38,53], whereas the vector of $B$. vallesianus is unknown). Nevertheless, from our findings showing that B. vallesianus and B. mucro- natus are both pathogenic to pine seedlings, we cannot reject the hypothesis that these two Bursaphelenchus spp. are involved in the observed pine decline in the Swiss Valais. Even though the nematodes might not be a primary cause of the pine decline, they could contribute to the decline process as secondary pathogens.

Moreover, the observed relationship between water regime and mortality in our experiment corresponded well to field observations reporting that pine mortality increases after hot and dry summers (49). However, pine decline in the Valais seems to be a complex phenomenon involving multiple abiotic and biotic factors $(5,49)$. Besides nematodes, other biotic agents possibly contribute to pine decline, including bark- and wood-boring insects (60), blue-stain fungi (U. Heiniger and D. Rigling, unpublished results), and mistletoes (20).

\section{ACKNOWLEDGMENTS}

We thank H. Braasch and Ute Schönfeld for their introduction into the rearing of nematodes and the inoculation procedure, U. Heiniger for suggestions and discussions in the course of manuscript preparation, H. Blauenstein and R. Graf for their help with sample processing, W. Burgermeister and E. Buchbach-Woldt for internal transcribed spacerrestriction fragment length polymorphism analysis, and S. Dingwall for English corrections.

\section{LITERATURE CITED}

1. Akbulut, S., Braasch, H., Baysal, I., Brandstetter, M., and Burgermeister, W. 2007. Description of Bursaphelenchus anamurius sp. $\mathrm{n}$. (Nematoda: Parasitaphelenchoidae) from Pinus brutia in Turkey. Nematology 9:859867.

2. Akbulut, S., Vieira, P., Ryss, A., Yuksel, B., Keten, A., Mota, M., and Valadas, V. 2006. Preliminary survey of the pinewood nematode in Turkey. OEPP/EPPO Bull. 36:538-542.

3. Akbulut, S., Yuksel, B., Serin, M., Baysal, I., and Erdem, M. 2007. Pathogenicity of Bursaphelenchus mucronatus in pine seedlings under greenhouse conditions. Turk. J. Agric. For. 31:169-173.

4. Bakke, A., Anderson, R. V., and Kvamme, T. 1991. Pathogenicity of the nematodes Bursaphelenchus xylophilus and B. mucronatus to Pinus sylvestris seedlings: a greenhouse test. Scand. J. For. Res. 6:407-412.

5. Bigler, C., Braeker, O. U., Bugmann, H., Dobbertin, M., and Rigling, A. 2006. Drought as inciting mortality factor in Scots pine stands of the Valais, Switzerland. Ecosystems 9:330343.

6. Blakeslee, G. M., Miller, T., and Esser, R. P. 1987. Observations on pine wood nematoderelated mortality of sand and slash pine seed orchard trees in Florida. Pages 40-49 in: Proc. Symp. Am. Phytopathol. Soc. Pathogenicity of the pine wood nematode. M. J. Wingfield, ed. Reno, NV.

7. Bolla, R. I., Winter, R. E. K., and Linit, M. J. 1986. Pathotypes of the pinewood nematode Bursaphelenchus xylophilus. J. Nematol. 18: 230-238.

8. Braasch, H. 1997. Wirts- und Pathogenitätsuntersuchungen mit dem Kiefernholznematoden (Bursaphelenchus xylophilus) aus Nordamerika unter mitteleuropäischen Klimabedingungen. Nachrichtenbl. Dtsch. Pflanzenschutzdienst (Berlin) 49:209-214.

9. Braasch, H. 2000. Influence of temperature and water supply on mortality of 3-year-old pine inoculated with Bursaphelenchus xylophilus and B. mucronatus. Nachrichtenbl. Dtsch. Pflanzenschutzdienst (Berlin) 52:244-249.

10. Braasch, H., Burgermeister, W., and Gu, J. 2009. Revised intra-generic grouping of Bursaphelenchus Fuchs, 1937 (Nematoda: Aphelenchoididae). J. Nematod. Morphol. Syst. 12:65-88.

11. Braasch, H., Caroppo, S., Ambrogioni, L., Michalopoulos, H., Skarmoutsos, G., and Tomiczek, C. 1999. Pathogenicity of various Bursaphelenchus species to pines and implications to European forests. Pages 27-28 in: Proc. Int. Symp. Sustainability of Pine Forest in Relation to Pine Wilt and Decline. K. Futai, K. Togashi, and T. Ikeda, eds. Shokado, Tokyo.

12. Braasch, H., Schönfeld, U., Polomski, J., and Burgermeister, W. 2004. Bursaphelenchus vallesianus sp. n.-a new species of the Bur saphelenchus sexdentati group (Nematoda: Parasitaphelenchidae). Nematol. Mediterr. 32:71-79.

13. Bruhn, J. N., Pickens, J. B., and Stanfield, D. B. 1999. Probit analysis of oak wilt transmission through root grafts in red oak stands. For Sci. 37:38-44.

14. Brzeski, M. W., and Brzeski, J. 1997. Survey of Bursaphelenchus (Nematoda: Aphelenchoididae) species in pine wood of Poland. Fragmenta. Faunistica, Muzeum Inst. Zool. PAN. 40:103-109.

15. Cao, A. X., Liu, X. Z., Zhu, S. F., and Lu, B. S. 2005. Detection of the pinewood nematode Bursaphelenchus xylophilus, using a real-time polymerase chain reaction assay. Phytopathology 95:566-571.

16. Caroppo, S., Ambrogioni, L., Cavalli, M., and Coniglio, D. 1998. Occurrence of the pine wood nematodes, Bursaphelenchus spp. and their possible vectors in Italy. Nematol. Mediterr. 26:87-92.

17. Croisé, L., Lieutier, F., Cochard, H., and Dreyer, E. 2001. Effects of drought stress and high density stem inoculations with Leptographium wingfieldii on hydraulic properties of young Scots pine. Tree Physiol. 21:427-436.

18. Daub, M. 2008. Investigations on pathogenicity, invasion biology and population dynamics of the pine wood nematode Bursaphelenchus xylophilus (Steiner und Buhrer 1934) Nickle 1970 in European conifers. Dissertation, University of Bonn, Germany.

19. Desprez-Loustau, M. L., Marçais, B., Nageleisen, L. M., Piou, D., and Vannini, A. 2006. Interactive effects of drought and pathogens in forest trees. Ann. For. Sci. 63:597-612.

20. Dobbertin, M., and Rigling, A. 2006. Pine mistletoe (Viscum album ssp. austriacum) contributes to Scots pine (Pinus sylvestris) mortality in the Rhone valley of Switzerland. For. Pathol. 36:309-322.

21. Dwinell, D. L. 1985. Relative susceptibility of five pine species to three populations of the pinewood nematode. Plant Dis. 69:440-442.

22. Franceschi, V. R., Krokener, P., Christiansen, E., and Krekling, T. 2005. Anatomical and chemical defenses of conifer bark against bark beetles and other pests. New Phytol. 67:353376.

23. Fukuda, K. 1997. Physiological process of the symptom development and resistance mechanism in pine wilt disease. J. For. Res. 2:171181.

24. Hacke, U. G., Sperry, J. S., and Pittermann, J. 2000. Drought experience and cavitation resistance in six shrubs from the Great Basin, Utah. Basic Appl. Ecol. 1:31-41.

25. Hacke, U. G., Sperry, J. S., Pockman, W. T. Davis, S. D., and McCulloh, K. A. 2001. Trends in wood density and structure are linked to prevention of xylem implosion by negative pressure. Oecologia 126:457-461

26. Hacke, U. G., Stiller, V., Sperry, J. S., Pittermann, J., and McCulloh, K. A. 2001. Cavita- 
tion fatigue. Embolism and refilling cycles can weaken the cavitation resistance of xylem. Plant Physiol. 125:779-786.

27. Ichihara, Y., Fukuda, K., and Suzuki, K. 2000. Early symptom development and histological changes with migration of Bursaphelenchus xylophilus in seedling tissues of Pinus thunbergii. Plant Dis. 84:675-680.

28. Kaneko, S. 1989. Effect of light intensity on the development of pine wilt disease. Can. J. Bot. 67:1861-1864.

29. Kawaguchi, E., Gyokusen, K., and Saito, A. 1999. Behaviour of Bursaphelenchus xylophilus and the development of pine wilt disease under shaded condition. Pages 39-41 in: Proc. Int. Symp. Sustainability of Pine Forest in Relation to Pine Wilt and Decline. K. Futai, K. Togashi, and T. Ikeda, eds. Shokado, Tokyo.

30. Kulinich, O. A., Kruglic, I., Eroshenko, A. S., and Kolossova, N. V. 1994. Occurrence and distribution of the nematode Bursaphelenchus mucronatus in the Russian Far East. Russ. J. Nematol. 2:113-119.

31. Kuroda, K. 1991. Mechanism of cavitation development in the pine wilt disease. Eur. J. For. Pathol. 21:82-89.

32. Kuroda, K. 2008. Defense systems of Pinus densiflora cultivars selected as resistant to pine wilt disease. Pages 313-320 in: Pine Wilt Disease: A Worldwide Threat to Forest Ecosystems. M. Mota and P. Vieira, eds. Springer.

33. Kuroda, K., Yamada, T., and Ito, S. 1991. Bursaphelenchus xylophilus induced pine wilt: factors associated with resistance. Eur. J. For. Pathol. 21:430-438.

34. Lanier, G. N. 1988. Therapy for Dutch elm disease. J. Arboric. 14:229-232.

35. Mamiya, Y. 1984. Behaviour of the pine wood nematode, Bursaphelenchus xylophilus, associated with the disease development of pine wilt. Pages 14-25 in: Proc. USA-Japan Seminar, The Resistance Mechanisms of Pines against Pine Wilt Disease. V. Dropkin, ed. Honolulu, HI.

36. Mamiya, Y. 2004. Pine wilt disease in Japan. Pages 9-20 in: The Pine Wood Nematode, Bursaphelenchus xylophilus. M. Mota and P. Vieira, eds. Brill Academic Publishers, The Netherlands.

37. Mamiya, Y. 2008. Histopathological observations of Bursaphelenchus xylophilus in symptomatic tissues of pinewood. Pages 321-334 in: Pine Wilt Disease: A Worldwide Threat to Forest Ecosystems. M. Mota and P. Vieira, eds. Springer

38. Mamiya, Y., and Enda, N. 1979. Bursaphelenchus mucronatus N. sp. (Nematoda: Aphelenchoididae) from pine wood and its biology and pathogenicity to pine trees. Nematologica 25:353-361.
39. McNamara, D. G. 2004. Quarantine concerns about the methods used to demonstrate pathogenicity of Bursaphelenchus spp. Pages 187197 in: The Pine Wood Nematode, Bursaphelenchus xylophilus. M. Mota and P. Vieira, eds. Brill Academic Publishers, The Netherlands.

40. Melakeberhan, H., and Webster, J. M. 1990. Relationship of Bursaphelenchus xylophilus population density to mortality of Pinus sylvestris. J. Nematol. 22:297-302.

41. Michalopoulos-Skarmoutsos, H., Skarmoutsos, G., Kalapanida, M., and Karageorgos, A. 2004. Surveying and recording of nematodes of the genus Bursaphelenchus in conifer forests in Greece and pathogenicity of the most important species. Pages 113-126 in: The Pine Wood Nematode, Bursaphelenchus xylophilus. M. Mota and P. Vieira, eds. Brill Academic Publishers, The Netherlands.

42. Mota, M. M., Braasch, H., Bravo, M. A., Penas, A. C., Burgermeister, W., Metge, K., and Sousa, H. 1999. First report of Bursaphelenchus xylophilus in Portugal and in Europe. Nematology 1:727-734.

43. Mückenhausen, E. 1982. Pages 305-338 in: Die Bodenkunde und ihre geologischen, geomorphologischen, mineralogischen und petrologischen Grundlagen, 2nd ed. DLG-Verlag, Frankfurt am Main, Germany.

44. Panesar, T. S., and Sutherland, J. R. 1989. Pathogenicity of Canadian isolates of the Bursaphelenchus xylophilus (pine wood nematode) to provenance of Pinus sylvestris and Pinus contora as grown in Finland: a greenhouse study. Scand. J. For. Res. 4:549-557.

45. Pennypacker, B. W., Leath, K. T., and Hill, R. R., Jr. 1991. Impact of drought stress on the expression of resistance to Verticillium alboatrum in Alfalfa. Phytopathology 81:10141024.

46. Polomski, J., and Kuhn, N. 1998. Pages 199208 in: Wurzelsysteme, 1st ed. Haupt-Verlag, Bern, Switzerland.

47. Polomski, J., Rigling, D., and Schweingruber, F. 2008. Development of external and internal symptoms in pine seedlings (Pinus sylvestris) due to inoculation with Bursaphelenchus vallesianus. Pages 335-344 in: Pine Wilt Disease: A Worldwide Threat to Forest Ecosystems. M. Mota and P. Vieira, eds. Springer.

48. Polomski, J., Schönfeld, U., Braasch, H., Dobbertin, M., Burgermeister, W., and Rigling, D. 2006. Occurrence of Bursaphelenchus species in declining Pinus sylvestris in a dry Alpine valley in Switzerland. For. Pathol. 36:110118.

49. Rebetez, M., and Dobbertin, M. 2004. Climate change may already threaten Scots pine stands in the Swiss Alps. Theor. Appl. Climatol. 79:1-9.
50. Riga, E., Sutherland, J. R., and Webster, J. M. 1991. Pathogenicity of pinewood nematode isolates and hybrids to Scots pine seedlings. Nematologica 37:285-292.

51. Rouault, G., Candau, J. N., Lieutier, F., Nageleisen, L. M., Martin, J. C., and Warzée, N. 2006. Effects of drought and heat on forest in sect populations in relation to the 2003 drought in Western Europe. Ann. For. Sci. 63:13-624.

52. Rutherford, T., Riga, E., and Webster, J. 1992. Temperature-mediated behavioural relationships in Bursaphelenchus xylophilus, B. тисronatus and their hybrids. J. Nematol. 24:40 44

53. Schönfeld, U., Braasch, H., Burgermeister, W. and Bröther, H. 2008. Investigation on woodinhabiting nematodes of the Genus Bursaphelenchus in pine forests in the Brandenburg province, Germany. Pages 69-73 in: Pine Wilt Disease: A Worldwide Threat to Forest Ecosystems. M. Mota and P. Vieira, eds. Springer.

54. Skarmoutsos, G., and MichalopoulosSkarmoutsos, H. 2000. Pathogenicity of Bursaphelenchus sexdentati, Bursaphelenchus leoni and Bursaphelenchus hellenicus on European pine seedlings. For. Pathol. 30:149156.

55. Suzuki, K. 1987. Influence of water stress on disease development. Pathogenicity of the pine wood nematode. Pages 5-13 in: Proc. Symp. Am. Phytopathol. Soc. Etiology of Pine Wilt and Vector Relationships of Bursaphelenchus xylophilus. M. J. Wingfield, ed. Reno, NV.

56. Suzuki, K. 2002. Pine wilt disease-a threat to pine forest in Europe. Dendrobiology 48:7174

57. Thorne, G. 1961. Pages 48-49 in: Principles of Nematology. McGraw-Hill, New York.

58. Tyree, M. T., and Sperry, J. S. 1989. Vulnerability of xylem to cavitation and embolism Annu. Rev. Plant Physiol. Mol. Biol. 40:19-38.

59. Utsuzawa, S., Fukuda, K., and Sakaue, D. 2005. Use of magnetic resonance microscopy for the non-destructive observation of xylem cavitation caused by pine wilt disease. Phytopathology 95:737-743.

60. Wermelinger, B., Rigling, A., SchneiderMathis, D., and Dobbertin, M. 2008. Assessing the role of bark- and wood-boring insects in the decline of Scots pine (Pinus sylvestris) in the Swiss Rhone valley. Ecol. Entomol 33:239-249

61. Zhao, L., Wei, W., Liu X., Kang, L., and Sun, J. 2007. A novel rapid sampling method for pinewood nematode, Bursaphelenchus xylophilus (Nematoda: Parasitaphelenchidae). Can. J. For. Res. 37:1867-1872

62. Zimmermann, M. H. 1983. Pages 44-59 and 105-125 in: Xylem Structure and the Ascent of Sap. Springer, Berlin. 